\title{
Effect of surface texturing on cast iron reciprocating against steel under starved lubrication conditions: A parametric study
}

\author{
F. Saeidi, B. Meylan, P. Hoffmann, K. Wasmer ${ }^{1}$ \\ Advanced Materials Processing Laboratory, Swiss Federal Laboratories for Materials Science and \\ Technology (Empa), Feuerwerkerstrasse 39, 3602 Thun, Switzerland.
}

\begin{abstract}
This study investigates the effect of laser surface texturing on the friction behavior and the lifetime of grey cast iron reciprocating under starved lubrication conditions. Five geometrical texture parameters (feature depth, diameter, length, area fraction and sliding direction) were studied using a design of experiments (DoE) approach by developing a fractional factorial design. Reciprocal sliding tests were carried out for the cast iron-steel tribo-pair at a pressure of $24 \mathrm{MPa}$ and a frequency of $6 \mathrm{~Hz}$. DoE results revealed that the geometrical parameters of micro-textures interact in a complex manner. Hence, for better understanding the effect of surface texturing on the tribological performance, the interactions between geometrical parameters need to be considered. It is found that except the following main factors: diameter and area fraction, mainly interactions of geometrical parameters have significant impact on the coefficient of friction. It is also observed that micro-textures could increase the lifetime of tribo-systems sliding under starved conditions. Based on the DoE analysis, an optimum micro-texture having a relatively low coefficient of friction and a long lifetime are achieved with the following (geometrical) parameters: a depth of $50 \mu \mathrm{m}$, a diameter of $100 \mu \mathrm{m}$, a length of $500 \mu \mathrm{m}$, an area fraction of $5 \%$, and the sliding direction perpendicular to the micro-textures.
\end{abstract}

Keywords: Laser surface texturing, Cast iron, Starved lubrication, Scuffing, Design of experiments

\footnotetext{
${ }^{1}$ Corresponding authors: Fatemeh Saeidi; fatemeh.saeidi@empa.ch

Kilian Wasmer; E-mail: kilian.wasmer@empa.ch, Tel: +41 5876562 71; Fax: +41 3322844 90;
} 


\section{Introduction}

There is an increasing need for tribo-systems that can withstand demanding sliding contact conditions (e.g. high loads, sliding speeds and temperatures) while simultaneously keeping friction and wear rate at a low level. This is especially true in the automotive industry [1], where researchers continuously search for more effective lubrication strategies and surface designs for sliding surfaces. Surface texturing as a surface design method has been successfully used in many applications to reduce friction and improve the tribological performance [2-5]. Depending on the contact situation (hydrodynamic, mixed or boundary contact), improvement of the lubrication by surface texturing can be achieved essentially through three different mechanisms. The first mechanism originated from the work of Hamilton et al. [6] in the 1960s. The idea was to enhance the lubrication of parallel rotaryshaft face seals by having an additional hydrodynamic pressure produced by micro-textures under conditions of thick-film lubrication. For the boundary or starved lubrication conditions, a secondary lubrication mechanism is also available through the supply of the lubricant inside the micro-textures to the contact area and acting as micro-reservoirs [7-9]. The third mechanism, operational under both dry and lubricated conditions, is the entrapment of wear particles inside the micro-textures [10-12]. Debris is trapped within the features of the micro-texture, effectively removing abrasive particles from the sliding contact and decreasing friction and wear in the tribo-system.

The effect of surface texturing on the tribological performance has been widely investigated for surfaces sliding under the hydrodynamic lubrication $[9,13-15]$, boundary and/or mixed lubrication $[12,16,17]$ conditions. For such lubrication conditions, there are also numerical studies showing the optimum geometrical parameters of micro-textures $[3,6,18,19]$. Rather few studies focus on the effect of micro-textures for surfaces sliding under starved lubrication [4, 20]. Despite a strong correlation among micro-texture parameters [21], as of yet no systematical study to find how geometrical parameters of micro-textures interact under different sliding conditions has been performed. Therefore, the fundamental aspects responsible for improving the tribological performance are not yet fully understood. This study uses a factorial analysis as an efficient method to investigate the combination effects of geometrical parameters of micro-textures on the friction behavior and the 
lifetime of cast iron reciprocating against steel under starved lubrication conditions. In this work, the conditions of an industrial semi journal bearing used in a cutting machine are simulated.

\section{Experimental details}

\subsection{Laser surface texturing}

In this study, 16 different micro-textures were produced by laser ablation. All the details regarding the design of micro-textures are given in Section 2.2. The ablation was performed on the mirrorpolished grey cast iron samples $\left(R_{a} \approx 0.4 \mu \mathrm{m}\right)$ using a nanosecond (ns) pulsed near-infrared laser with a wavelength of $1064 \mathrm{~nm}$. Ns-laser texturing inevitably results in the formation of a raised rim around each micro-texture due to re-solidification of the molten and pushed up material (see Fig. 1a). Kovalchenko et al. [22] showed that these rims have a negative effect on the tribological performance of textured surfaces. Therefore, in this work, all textured samples were polished after laser texturing with diamond polishing compound ( $30 \mathrm{~s}$ with $6 \mu \mathrm{m}$ and 30-90 s with $1 \mu \mathrm{m}$ in size) to remove the rims. Samples were then cleaned in an ultrasonic bath with ethanol to remove any polishing compounds or polishing debris. This was verified by confocal and optical microscopy to be certain that no particles from polishing compound were found inside the micro-textures. The absence of raised rims was verified after polishing via confocal microscopy imaging and presented as a cross sectional line scan through a dimple in Fig. $1 b$.

a

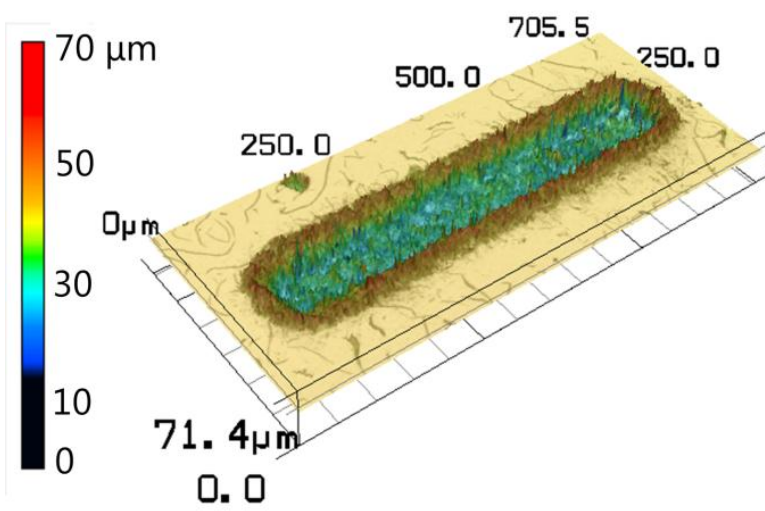

b

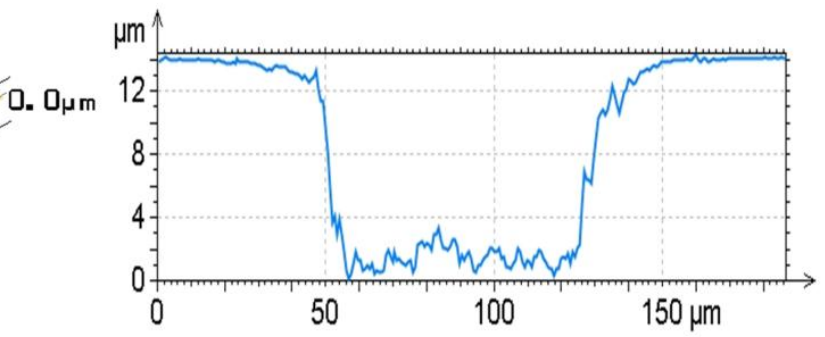

Fig. 1: (a) 3D contour map of micro-texture produced by ns-laser ablation (Tx10) before removing the rims, (b) Surface profile of this micro-texture after polishing the rims. 


\subsection{Design of experiments}

Factorial design enables the simultaneous analysis of several factors ${ }^{1}$ and the estimation of both their individual and interaction effects. This statistical method provides a wider view and could bring some light to the understanding of the output results in any experimental test design [23]. A two-level factorial design or $2^{k}$ factorial design, where $k$ corresponds to the number of factors and each factor can have 2 levels, is widely used for factor screening experiments [24]. In order to investigate the effects of the geometrical texture parameters on the tribological performance based on the design of experiments (DoE), five geometrical factors were selected: the depth $(h)$, the diameter $(d)$, the length $(l)$, the area fraction of micro-textures $(f)$, and the sliding direction relative to the major axis of microtextures $(\alpha)$, as described in Fig. 2. Each factor is described by a high and a low level and their real values as well as coded values are listed in Table 1. Note that the real geometrical values obtained by laser ablation are provided in the appendix (Table A.1). The $90^{\circ}$ sliding direction was selected based on the numerical simulation and experimental results showing that the higher lubricant film thickness for micro-textures perpendicular to the sliding direction $[15,25]$. The low level for sliding direction $(\alpha)$ could be selected at $0^{\circ}$, but there are publications $[15,17]$ mentioning the disadvantages of having textures parallel to the sliding direction. Therefore, $0^{\circ}$ was disregarded and $15^{\circ}$ was selected for the low level. Many researchers have reported an optimum area fraction of $5 \%$, and an increase in the COF by producing micro-textures more than $10-20 \%$ of the total area $[5,15,26]$. Similarly, the low and high levels for the other factors are selected based on the literature review $[5,13,27,28]$.

The number of experiments required by a $2^{k}$ factorial design having 5 factors is 32 . As the sample preparation and running the experiments, plus the repetitions are highly time consuming, the number of experiments was reduced by using a fractional factorial design [29]. The strategy of the fractional factorial design selected in this work is based on one-half fraction or $2^{5-1}$ design, which decreased the number of experiments by a factor 2 leading to 16 experiments. The test matrix is obtained by combining the low and the high level values of Table 1, and it is shown in Table 2 . This design allows making 16 experiments with $l d h f \alpha$ as the generator and setting the fifth factor $(\alpha)$ equal to $l d h f$. Since,

\footnotetext{
${ }^{1}$ Factors are those input parameters/variables studied by factorial design.
} 
the generator is $I=l d h f \alpha$, each main effect is aliased with a four-factor interaction (e.g. $l \rightarrow l+d h f \alpha)$ and every two-factor interaction with a three-factor interaction (e.g. $l d \rightarrow l d+h f \alpha$ ). Thus, this design is of resolution $\mathrm{V}$, and it is expected to provide excellent information regarding the main effects and the two-factor interaction effects [24]. Eq. (1) shows our first degree polynomial model with interactions:

$$
Y=a_{o}+\sum_{i=1}^{5} a_{i} X_{i}+\sum_{i \neq j}^{5} a_{i j} X_{i} X_{j}+\varepsilon
$$

where $Y$ is the experimental response, $a_{0}$ is a constant, $X_{i}$ is the factor, $a_{i}$ is the main effect coefficient (half-effect) associated to the factor $X_{i}, a_{i j}$ is the interaction effect coefficients (half-effect) and $\varepsilon$ the error observed in the response $Y$ (also known as the residual). Coefficients or half-effects can be calculated using the following equations:

$$
\hat{\alpha}=\frac{1}{N} X^{T} Y
$$

where $\hat{\alpha}$ is the model coefficient matrix (presented in Table 2), $N$ the total number of runs and $X^{T}$ the transpose of the model matrix. The relative half-effect $(R H E)$ is then defined as the ratio of the halfeffect and the constant $\left(a_{0}\right)$.

Even though a perfect linearity in the factor effects is unnecessary, this assumption in the two-level factorial design is usually a potential concern [24]. Consequently, a center point or a zero level is also added to determine whether a curvature exists in the model (Tx17 and Tx18 in Table 2).

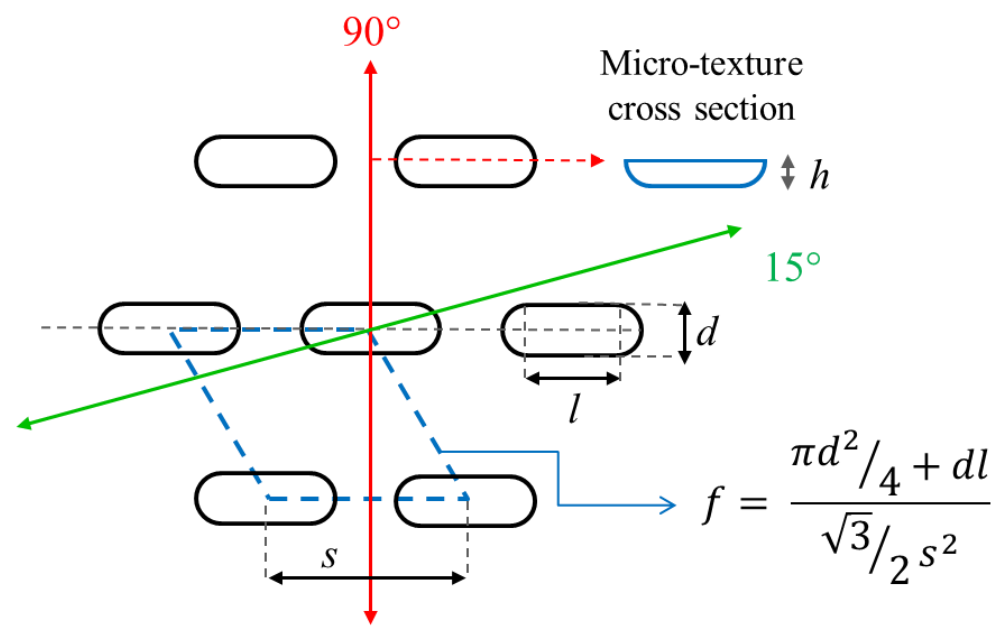

Fig. 2: Schematic of micro-textures parameters and sliding direction used as input factors for DoE study. 
Table 1: Factors, levels and coded values of the design of experiments.

\begin{tabular}{cccc}
\hline Factors & Low level & Center point & High level \\
\hline Depth $(h) \mu \mathrm{m}$ & 10 & 30 & 50 \\
Diameter $(d) \mu \mathrm{m}$ & 100 & 200 & 300 \\
Length $(l) \mu \mathrm{m}$ & 100 & 300 & 500 \\
Area fraction $(f)$ & 0.05 & 0.07 & 0.1 \\
Sliding direction $(\alpha)$ deg. & 15 & 52 & 90 \\
\hline Code & $\mathbf{- 1}$ & $\mathbf{0}$ & $\mathbf{1}$ \\
\hline
\end{tabular}

Table 2: Matrix of experiments including the response 1 (average coefficient of friction, $\bar{\mu}$ ) and the response 2 (lifetime, $T_{t}$ ) for textured cast iron samples

\begin{tabular}{|c|c|c|c|c|c|c|c|c|c|c|c|c|c|c|c|c|c|c|c|}
\hline \multirow{2}{*}{$\begin{array}{c}\text { Sample } \\
\text { name }\end{array}$} & \multirow{2}{*}{$\begin{array}{l}\text { Run } \\
\text { order }\end{array}$} & \multicolumn{6}{|c|}{ Main effects } & \multicolumn{10}{|c|}{ Interactions } & \multirow{2}{*}{$\begin{array}{c}\text { Response } 1 \\
\bar{\mu}\end{array}$} & \multirow{2}{*}{$\begin{array}{c}\text { Response } 2 \\
T_{t}[\mathrm{~min}]\end{array}$} \\
\hline & & $a_{0}$ & $h$ & $d$ & $l$ & $f$ & $\alpha=h d l f$ & hd & $h l$ & $h f$ & $h \alpha$ & $d l$ & $d f$ & $d \alpha$ & lf & $l \alpha$ & $f \alpha$ & & \\
\hline Tx1 & 6 & 1 & 1 & 1 & 1 & -1 & -1 & 1 & 1 & -1 & -1 & 1 & -1 & -1 & -1 & -1 & 1 & 0.108 & 161.3 \\
\hline Tx2 & 15 & 1 & 1 & -1 & 1 & -1 & 1 & -1 & 1 & -1 & 1 & -1 & 1 & -1 & -1 & 1 & -1 & 0.110 & 960.0 \\
\hline Tx3 & 1 & 1 & 1 & 1 & -1 & -1 & 1 & 1 & -1 & -1 & 1 & -1 & -1 & 1 & 1 & -1 & -1 & 0.112 & 119.7 \\
\hline $\mathrm{Tx} 4$ & 4 & 1 & 1 & -1 & -1 & -1 & -1 & -1 & -1 & -1 & -1 & 1 & 1 & 1 & 1 & 1 & 1 & 0.101 & 244.7 \\
\hline Tx5 & 13 & 1 & 1 & 1 & 1 & 1 & 1 & 1 & 1 & 1 & 1 & 1 & 1 & 1 & 1 & 1 & 1 & 0.149 & 104.6 \\
\hline Tх6 & 9 & 1 & 1 & -1 & 1 & 1 & -1 & -1 & 1 & 1 & -1 & -1 & -1 & 1 & 1 & -1 & -1 & 0.091 & 123.0 \\
\hline Tx7 & 2 & 1 & 1 & 1 & -1 & 1 & -1 & 1 & -1 & 1 & -1 & -1 & 1 & -1 & -1 & 1 & -1 & 0.166 & 482.4 \\
\hline Tx8 & 10 & 1 & 1 & -1 & -1 & 1 & 1 & -1 & -1 & 1 & 1 & 1 & -1 & -1 & -1 & -1 & 1 & 0.117 & 360.0 \\
\hline Тх9 & 7 & 1 & -1 & 1 & 1 & -1 & 1 & -1 & -1 & 1 & -1 & 1 & -1 & 1 & -1 & 1 & -1 & 0.129 & 402.9 \\
\hline Tx10 & 16 & 1 & -1 & -1 & 1 & -1 & -1 & 1 & -1 & 1 & 1 & -1 & 1 & 1 & -1 & -1 & 1 & 0.116 & 87.8 \\
\hline Tx11 & 8 & 1 & -1 & 1 & -1 & -1 & -1 & -1 & 1 & 1 & 1 & -1 & -1 & -1 & 1 & 1 & 1 & 0.137 & 500.0 \\
\hline Tx12 & 12 & 1 & -1 & -1 & -1 & -1 & 1 & 1 & 1 & 1 & -1 & 1 & 1 & -1 & 1 & -1 & -1 & 0.119 & 188.6 \\
\hline Tx13 & 5 & 1 & -1 & 1 & 1 & 1 & -1 & -1 & -1 & -1 & 1 & 1 & 1 & -1 & 1 & -1 & -1 & 0.125 & 72.2 \\
\hline Tx14 & 3 & 1 & -1 & -1 & 1 & 1 & 1 & 1 & -1 & -1 & -1 & -1 & -1 & -1 & 1 & 1 & 1 & 0.116 & 133.5 \\
\hline Tx15 & 14 & 1 & -1 & 1 & -1 & 1 & 1 & -1 & 1 & -1 & -1 & -1 & 1 & 1 & -1 & -1 & 1 & 0.120 & 463.0 \\
\hline Tx16 & 11 & 1 & -1 & -1 & -1 & 1 & -1 & 1 & 1 & -1 & 1 & 1 & -1 & 1 & -1 & 1 & -1 & 0.103 & 433.2 \\
\hline Tx17 & 17 & 0 & 0 & 0 & 0 & 0 & 0 & 0 & 0 & 0 & 0 & 0 & 0 & 0 & 0 & 0 & 0 & 0.108 & 520.0 \\
\hline Tx18 & 18 & 0 & 0 & 0 & 0 & 0 & 0 & 0 & 0 & 0 & 0 & 0 & 0 & 0 & 0 & 0 & 0 & 0.110 & 565.0 \\
\hline
\end{tabular}



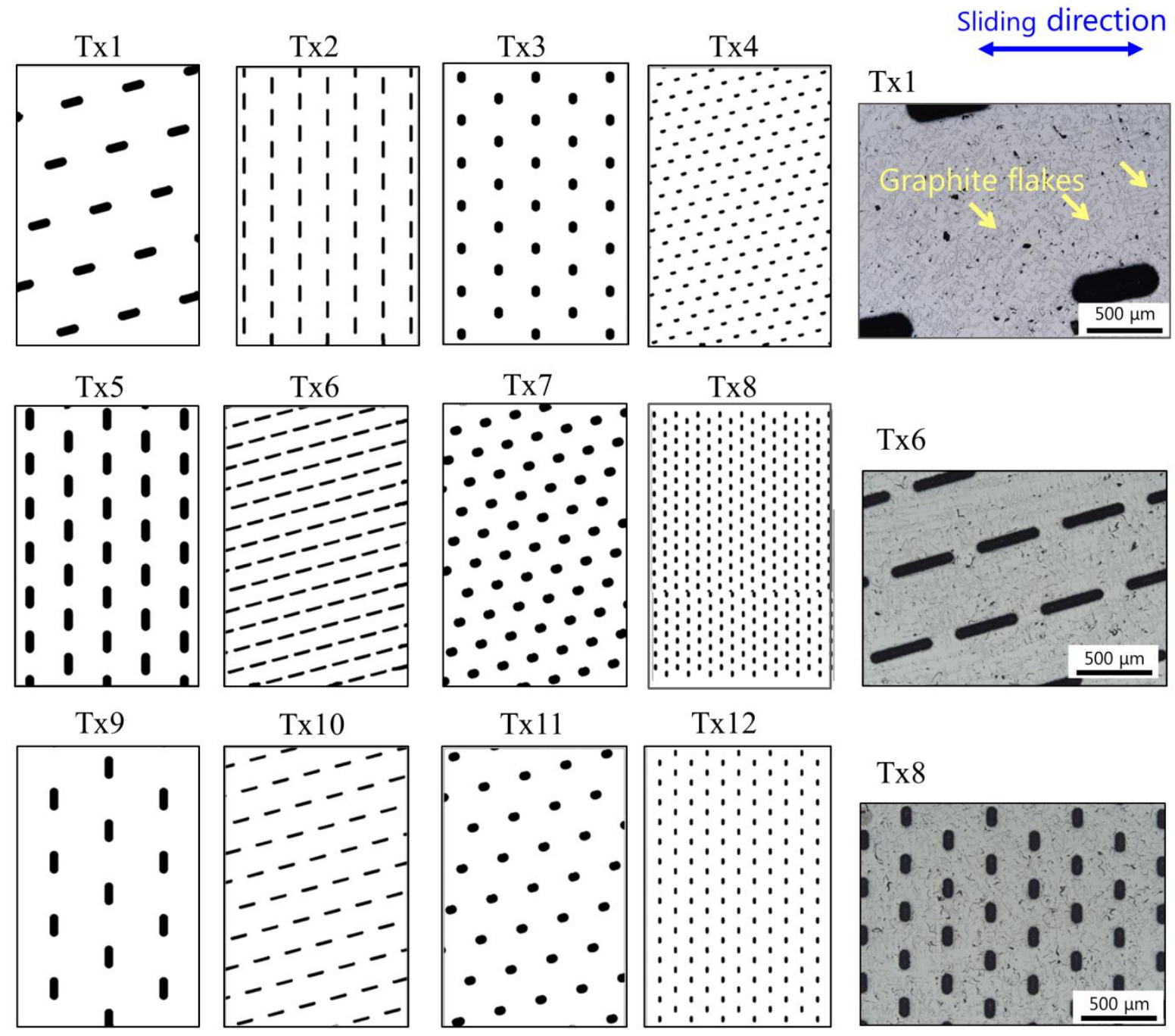

$\mathrm{Tx} 12$

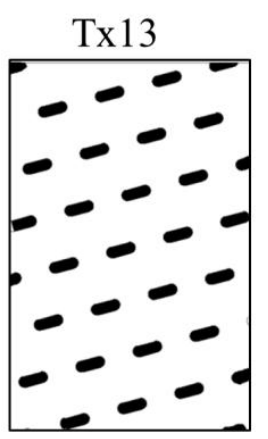

Tx14
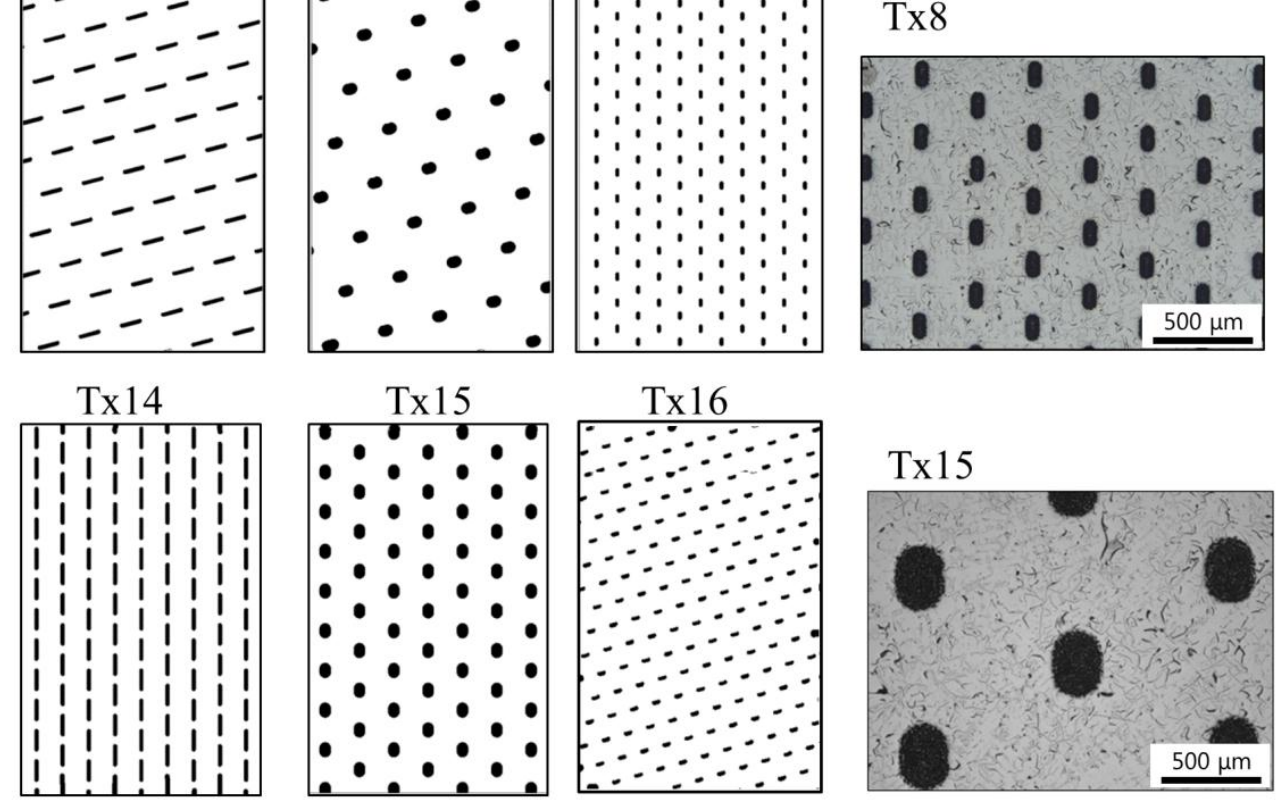

Fig. 3: The schematic of all micro-textures designed based on the DoE and values presented in Table 1 and Table 2 (left), and optical images of some micro-textures produced on cast iron samples (right).

\subsection{Tribo-tests}

In order to simulate starved conditions and scuffing in a conformal contact like semi journal bearings, flat-on-flat configuration is selected. A reciprocating tribometer (SRV ${ }^{\circledR}$ III, Optimol Instruments Prüftechnik GmbH, Germany) is used, which is illustrated in Fig. 4. A special holder was employed for the counter-body to prevent inclination and provide flat-on-flat conditions. Several steps 
were established to make sure that the tribo-system has truly flat-on-flat conditions, and details are provided in the Appendix (counter-body preparation). The counter-body was made of hardened 42CrMo6 steel with a hardness value of $600 \mathrm{HV}$, which was loaded against an oil lubricated textured grey cast iron having a hardness of $200 \mathrm{HV}$. Their chemical compositions are presented in Table 3.

Sixteen tests were performed on un-textured polished cast iron samples as a reference. For textured samples, tribo-tests were carried out randomly (see the run order in Table 2) on different microtextures presented in Table 2. Three replication tests were conducted for Tx2, and two replications for the following textured samples: Tx3, Tx6, Tx7, Tx8, Tx11, Tx12 and Tx15 leading to 25 tests in total.

The same test conditions were used for all textured and un-textured samples. Both counter-body and the bottom sample were cleaned, prior to each test, in an ultrasonic bath with ethanol for 5 min. Since the presence of additives has strong effect on tribological behavior of contacts working under boundary and starved conditions [17, 30], and in order to highlight the effect of micro-textures, pure poly-alpha-olefin oil (PAO, viscosity $=8 \mathrm{cSt}$ ) was chosen as the lubricant. To enter the boundary and starved lubrication conditions, $0.4 \mu \mathrm{l} / \mathrm{cm}^{2}$ of PAO8 was homogeneously sprayed on the cast iron surface using a high precision spraying machine (AutoJet ${ }^{\circledR}$, Model 2250, USA). Afterwards, the sprayed oil was controlled by an accurate weighing $( \pm 0.1 \mathrm{mg})$. The counter-body was oscillating with a stroke of $4 \mathrm{~mm}$ at a frequency of $6 \mathrm{~Hz}$ and a constant nominal pressure of $24 \mathrm{MPa}(600 \mathrm{~N}$ load) in a chamber with controlled temperature and humidity $\left(35^{\circ} \mathrm{C}, 30 \% \mathrm{RH}\right)$. The friction torque is measured by a quartz force transducer with the precision $<1 \%$ placed beneath the bottom sample. Tests were continued until the detection of a sharp increase in the coefficient of friction (COF). This was considered as the failure of the cast iron surface (See Fig. 5). Immediately after the sharp increase in the COF, tests were stopped to avoid further damage to the surface. 
a

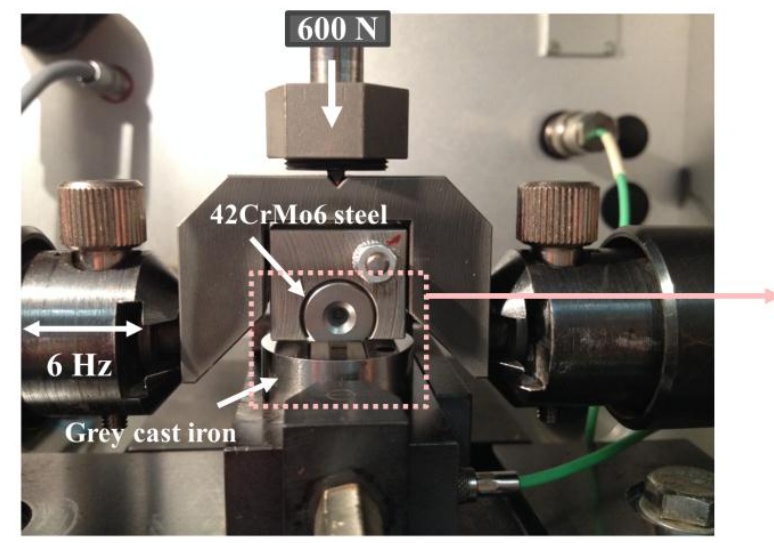

b

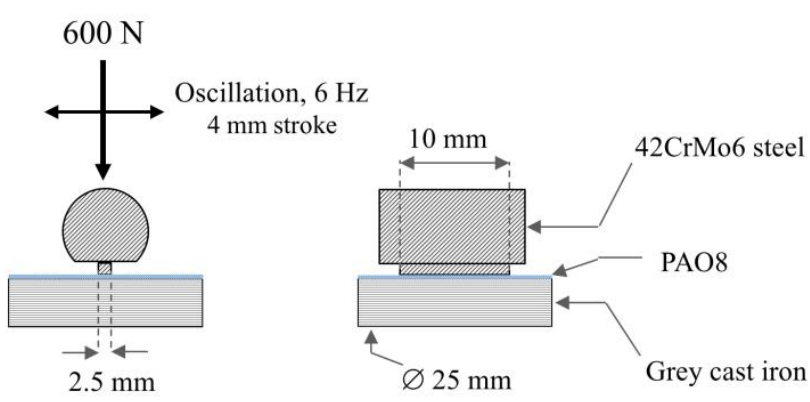

Front view
Side view

Fig. 4: Tribo-test set-up used for the present study (a) Reciprocating tribometer (SRV® III), and (b) schematic principle of the counter-body and the bottom sample.

Table 3: Chemical composition of the bottom sample (cast iron) and the counter-body (hardened steel)

\begin{tabular}{cccccccccc}
\hline & $\mathrm{C}$ & $\mathrm{Mn}$ & $\mathrm{Si}$ & $\mathrm{P}$ & $\mathrm{S}$ & $\mathrm{Cu}$ & $\mathrm{Cr}$ & $\mathrm{Mo}$ & $\mathrm{Fe}$ \\
\hline Grey cast iron & 2.890 & 0.940 & 1.470 & 0.036 & 0.059 & 1.000 & - & - & Balance \\
42CrMo4 steel & 0.400 & 0.750 & 0.330 & 0.035 & 0.028 & - & 1.010 & 0.160 & Balance \\
\hline
\end{tabular}

\section{Results and discussion}

Fig. 5a shows a typical curve of the friction behavior of un-textured cast iron reciprocating against hardened steel. In Fig. 5b, a very good repeatability of the tribo-tests of polished cast iron samples lubricated by PAO spraying (Fig. 5c) is illustrated. It is evident from Fig. 5a that during the first minutes of sliding, there is a sharp increase in the COF followed by a slower decrease. This behavior is defined as running-in, which is a common friction behavior for boundary lubricated metals [31]. Afterwards, sliding continues with a nearly stable friction behavior defined as steady-state regime. Then, a sharp increase in the COF takes place and failure occurs. Optical images and 3D color maps of cast iron and steel counter-body surfaces after failure are presented in Fig. 6. Materials transfer from cast iron to steel is apparent in the profile images (Fig. 6b and c) and proved by EDX (Fig. 6c and f). EDX spectrum of the steel counter-body in Fig. 6c shows a small peak of $\mathrm{Cr}$ and almost no peak for Si. In contrast, the spectrum of the transferred material (Fig. 6f) shows a clear peak for $\mathrm{Si}$, a stronger $\mathrm{C}$ peak and no peak for Cr. This is consistent with the cast iron composition values given in Table 3 . Such failure mechanism is defined as severe adhesive wear or scuffing [30, 32-34]. Despite having an identical sample preparation procedure and a very high reproducibility in the first 40 minutes of 
sliding (Fig. 5b), the duration of steady-state regime varies significantly between samples. This is due to sudden nature of scuffing and still unknown factors affecting this failure mechanism [32]. Such wide scatter has been also reported in scuffing resistance of piston ring materials reciprocating under constant load [35].

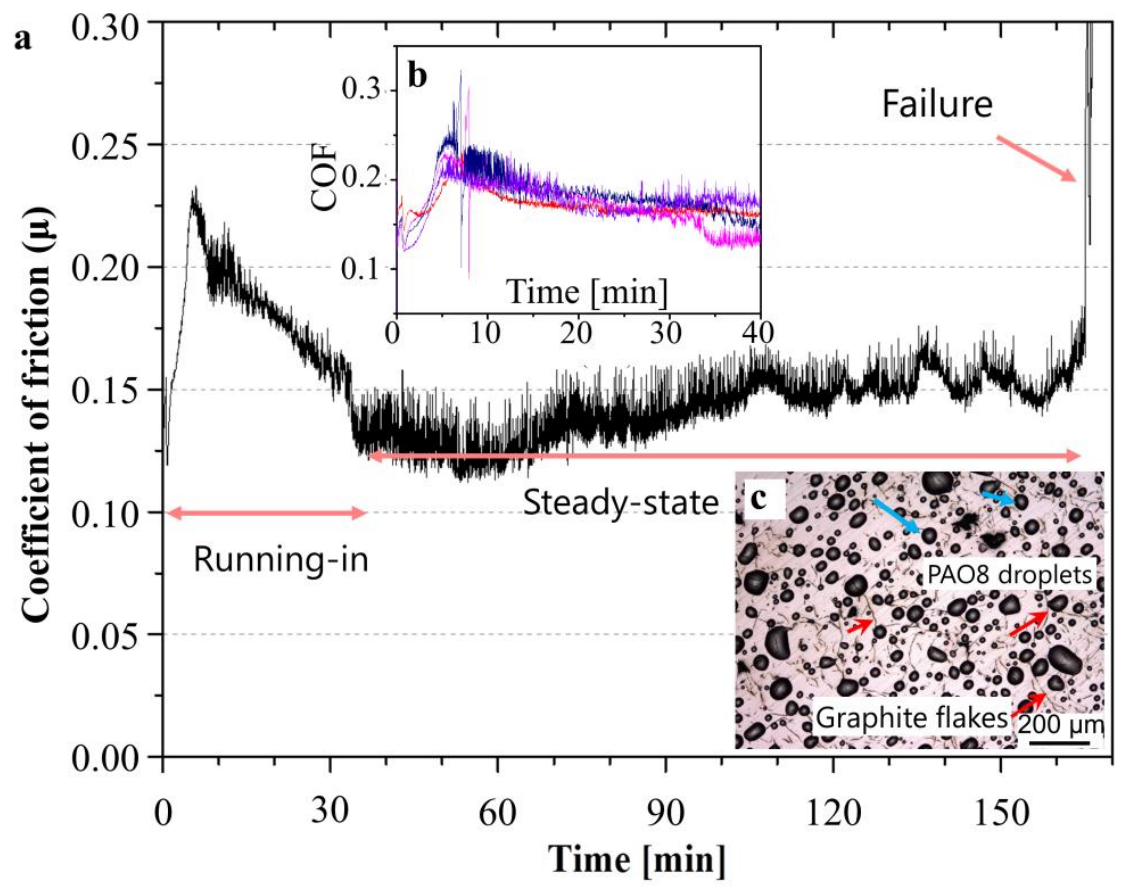

Fig. 5: (a) General friction behavior of un-textured cast iron reciprocating against steel under starved lubrication, (b) Demonstration of good repeatability of friction behavior and (c) Surface of polished grey cast iron with drops of PAO8 before tribo-test. 


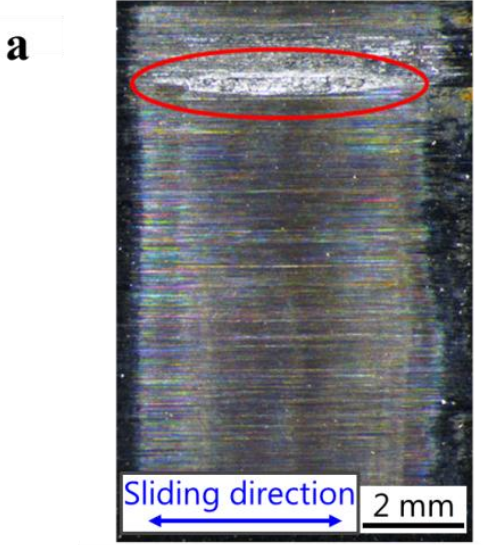

d

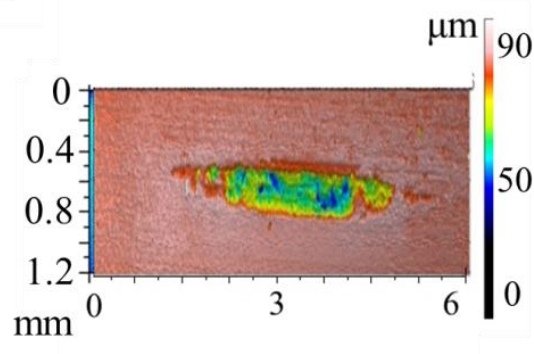

b
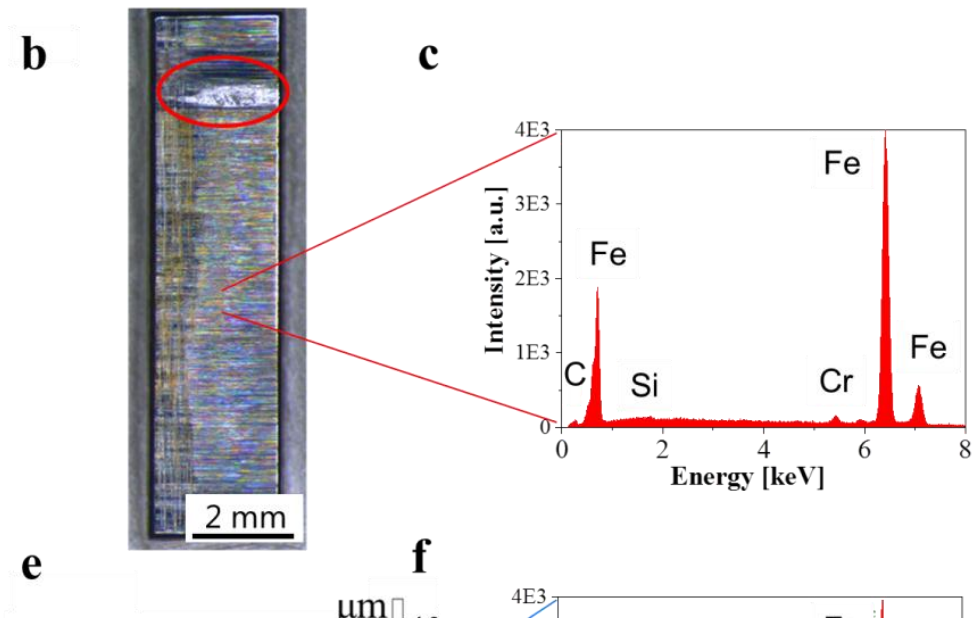
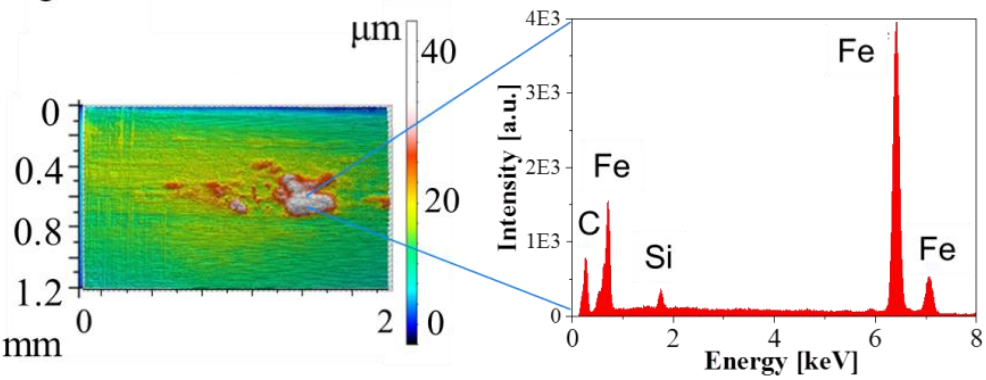

Fig. 6: (a, b) Optical images and (d, e) Optical profilometer 3D contour maps of respectively untextured cast iron and steel counter-body after failure, (c) EDX spectrum of the steel counter-body, and

(f) EDX spectrum of the material transferred on the counter-body (similar to cast iron spectrum not shown here).

\subsection{Effect of texturing on the coefficient of friction}

Tribo-tests revealed that all textured samples are showing almost the same typical friction behavior as the un-textured samples but a relatively lower COF during the steady-state regime and a higher COF during the running-in. Comparison of the typical friction behavior of two textured samples (Tx12 and Tx16) with an un-textured one is given in Fig. 7a. The higher values of COF during the running-in can be correlated to the higher local pressure on the initial asperities in contact. During the running-in, initially, only the highest peaks of the asperities are in contact, thus the initial contact area is very small leading to an extremely high local pressure [36]. Therefore, as schematically illustrated in Fig. $7 \mathrm{~b}$, in case of textured surfaces, as some high asperities are removed by texturing, it can be easily assumed that the local pressure is higher on the remaining asperities and consequently the COF is greater during the running-in until reaching the steady-state regime when the real contact area is equal in both cases. The average coefficient of friction $(\bar{\mu})$ measured between 100 and 150 min of sliding time is considered as the first response for the DoE and they are given in Table 2. The half-effects 
$(H E)$ are calculated from Eq. (2) and the relative half-effects $(R H E)$ for the main factors and the interactions are calculated and summarized in Table 4. The half-normal probability distribution is then plotted in Fig. 8a for $\bar{\mu}$. In this plot, the negligible effects have a normal distribution centered close to zero while the factors with a significant effect show a normal distribution centered at their corresponding large but undefined effect values [37]. Consequently, in Fig. 8a, the effects lying along the black line are considered to have negligible effects on the response whereas the factors and the interactions being off the line have a significant effect on $\bar{\mu}$. According to this plot, the two main effects $d$ and $f$ as well as the interactions: $h f, l \alpha, d f, d \alpha, h d$ are considered to have significant effects on $\bar{\mu}$. The half-effects for all terms (main factors and interactions) are plotted in Fig. $8 \mathrm{~b}$ in decreased order of their absolute values. The sequence of significant terms is as follows: $d(|H E|=0.011)>h f$ $(0.008)>l \alpha(0.0065)>d f(0.006)>d \alpha(0.005)>h d(0.004)>f(0.003)$. In this bar chart, $(+)$ effect means the corresponding factor or interaction has a positive coefficient in Eq. (1) (e.g. $+a_{i}$ or $+a_{i j}$ ) and (-) effect means the coefficient is negative (e.g. $-a_{i}$ or $-a_{i j}$ ).

a

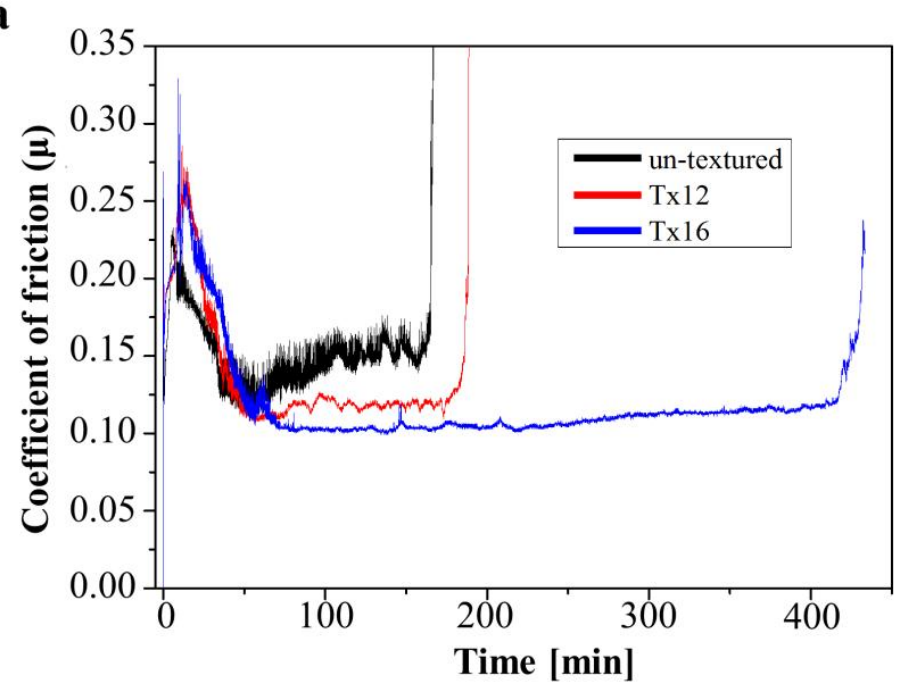

b

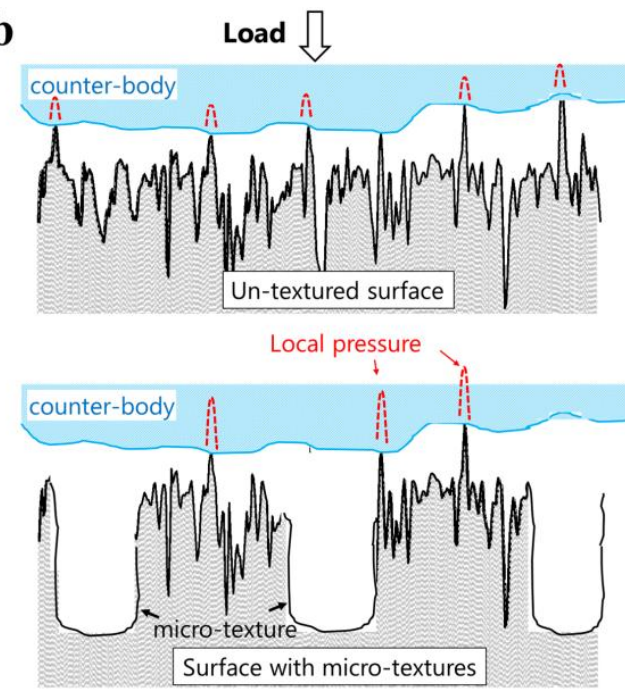

Fig. 7: (a) Friction behavior of two laser textured cast iron samples (Tx12 and Tx16) in comparison with an un-textured cast iron sliding under starved lubrication condition, (b) Schematic of initial contact and local pressure of un-textured and textured cast iron during running-in. 
Table 4: Calculated half-effects $(H E)$ and relative half-effects $(R H E)$ for response $1(\bar{\mu})$

\begin{tabular}{lcc}
\hline Parameter & $\boldsymbol{H E}$ & $\boldsymbol{R H E}(\boldsymbol{\%})$ \\
\hline$a_{0}$ & 0.1199 & - \\
$d$ & 0.0108 & 9.04 \\
$h f$ & 0.0081 & 6.76 \\
$l \alpha$ & 0.0065 & 5.40 \\
$d f$ & 0.0058 & 4.84 \\
$d \alpha$ & -0.0048 & -4.04 \\
$h d$ & 0.0037 & 3.10 \\
$f$ & 0.0035 & 2.88 \\
$h l$ & -0.0028 & -2.36 \\
$l$ & -0.0018 & -1.54 \\
$\alpha=h d l f$ & 0.0014 & 1.20 \\
$l f$ & -0.0012 & -0.97 \\
$h \alpha$ & 0.0012 & 0.96 \\
$d l$ & 0.0011 & 0.95 \\
$h$ & -0.0006 & -0.48 \\
$f \alpha$ & 0.0005 & 0.44 \\
\hline
\end{tabular}
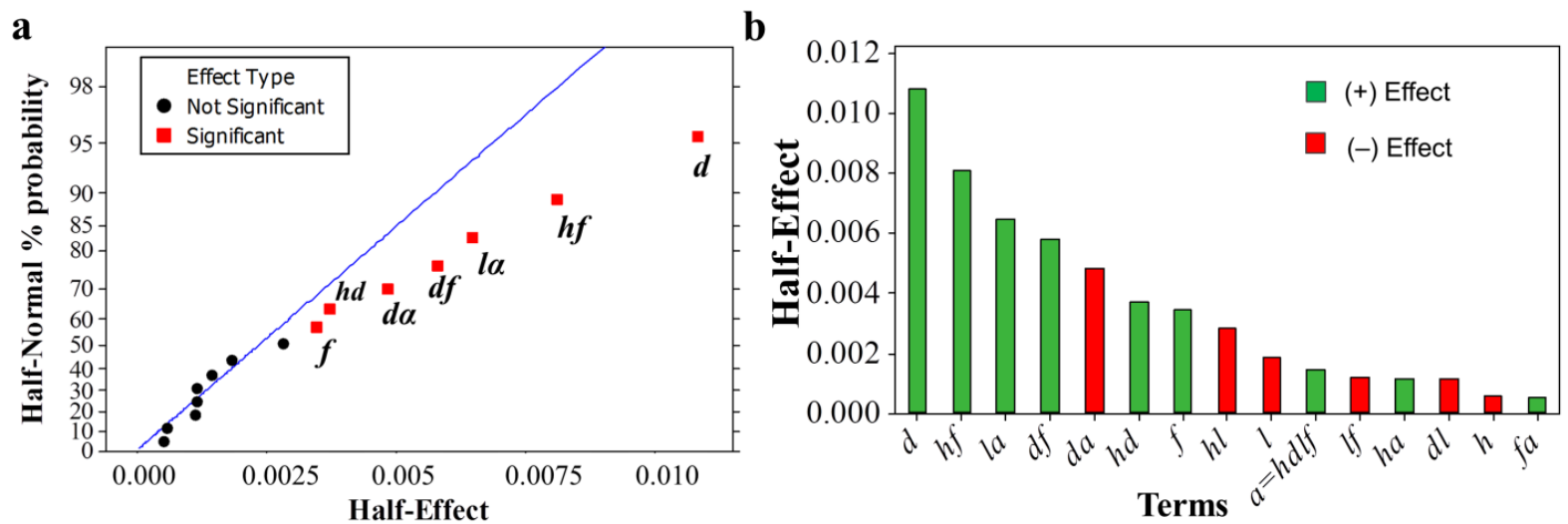

Fig. 8: (a) Half-normal probability plot showing the significant (red square) and not significant (black circle) effects and (b) Bar chart of the half-effects and their interactions affecting the average $\operatorname{COF}(\bar{\mu})$ in decreasing order, $(+)$ effects appear with $+\operatorname{sign}\left(+a_{i}\right.$ or $\left.+a_{i j}\right)$ in Eq.(1) and thus increase the response $(Y)$ and $(-)$ effects appear as $-a_{i} /-a_{i j}$ in this equation.

The significance of the selected terms is also evaluated using an analysis of variance (ANOVA) with a $95 \%$ confidence interval, and results are presented in Table 5. In this case, the terms with the probability of error ( $P$-value) less than 0.05 , which gives a $95 \%$ confidence interval are significant and those with $P$-value bigger than 0.1 can be neglected. The $F$ value presented in Table 4 is defined as:

$$
F=\frac{M S_{\text {Terms }}}{M S_{\text {Residual }}}
$$

where the mean square of terms $\left(M S_{\text {Terms }}\right)$ is the ratio of the sum of squares within terms to its degree of freedom $\left(S S_{\text {Terms }} / D F_{\text {Term }}\right)$, and similarly $M S_{\text {Residual }}=S S_{\text {Residual }} / D F_{\text {Residual }}$. Eq. (3) is a 
statistical test to verify the hypothesis of no differences in term means (so-called "null hypothesis") [24]. Normally, for effects having an $F$ greater than 3 times their standard error (residual) $(F>3)$, the null hypothesis is rejected [37]. As seen from Table 5, the model built based on the selected main factors and interactions has an $F$ value of about 13, which implies that the model is significant. The small $P$-value $(0.0005)$ in this table indicates that there is only a $0.05 \%$ probability that this model occurs due to noise. The $P$-values for all the selected terms are also less than 0.1 indicating that they are significant. Thus, the model achieved a $95 \%$ certainty.

As already mentioned, even with a linearity assumption, the $2^{k}$ factorial system works well [24]. However, it has been noted that if the interaction terms are added to the model, the model may be subjected to quadratic effects or second order curvature [24]. In such situation, it is advised to add center points to check the model for curvature. In Table 5, the $P$-value for the curvature is 0.98 , which means that there is no indication of quadratic effects and the curvature assumption can be neglected. Thus, a first order model with the main factors and interactions is suitable.

The final equation in terms of coded values is written as follows:

$$
\begin{aligned}
\bar{\mu}=+0.12+ & 0.011 d+0.003 f+0.004 h d+0.008 h f+0.006 d f-0.005 d \alpha \\
& +0.006 l \alpha
\end{aligned}
$$

The $R$-square value $\left(R^{2}\right)$, Adjusted- $R^{2}$ and Predicted- $R^{2}$ of this model are 0.91, 0.85, and 0.75, respectively. The Predicted- $R^{2}$ is good for the field of tribology, which indicates that the model can predict $\bar{\mu}$ with an appropriate precision. Fig. 9 plots the predicted $\bar{\mu}$ (calculated from Eq. 4 ) versus the experimentally measured values. A high correlation coefficient of 0.97 is observed. 
Table 5: Analysis of variance (ANOVA) for $\bar{\mu}$.

\begin{tabular}{lccccc}
\hline Parameter & SS & DF & $M S$ & $F$ & $P$-value \\
\hline Model & $4.9 \mathrm{E}-03$ & 7 & $7.0 \mathrm{E}-04$ & 12.96 & 0.0005 \\
$d$ & $1.9 \mathrm{E}-03$ & 1 & $1.9 \mathrm{E}-03$ & 34.61 & 0.0002 \\
$f$ & $1.9 \mathrm{E}-04$ & 1 & $1.9 \mathrm{E}-04$ & 3.52 & 0.0934 \\
$h d$ & $2.2 \mathrm{E}-04$ & 1 & $2.2 \mathrm{E}-04$ & 4.06 & 0.0747 \\
$h f$ & $1.1 \mathrm{E}-03$ & 1 & $1.1 \mathrm{E}-03$ & 19.34 & 0.0017 \\
$d f$ & $5.4 \mathrm{E}-04$ & 1 & $5.4 \mathrm{E}-04$ & 9.92 & 0.0117 \\
$d \alpha$ & $3.8 \mathrm{E}-04$ & 1 & $3.8 \mathrm{E}-04$ & 6.92 & 0.0273 \\
$l \alpha$ & $6.7 \mathrm{E}-04$ & 1 & $6.7 \mathrm{E}-04$ & 12.34 & 0.0066 \\
\hline Curvature & $2.0 \mathrm{E}-08$ & 1 & $2.0 \mathrm{E}-08$ & 0.00 & 0.9851 \\
\hline Residual & $4.9 \mathrm{E}-04$ & 9 & $5.4 \mathrm{E}-05$ & & \\
Lack of Fit & $2.9 \mathrm{E}-04$ & 8 & $3.6 \mathrm{E}-05$ & 0.18 & 0.9535 \\
Pure error & $2.0 \mathrm{E}-04$ & 1 & $2.0 \mathrm{E}-04$ & & \\
Total & $5.4 \mathrm{E}-03$ & 17 & & & \\
\hline
\end{tabular}

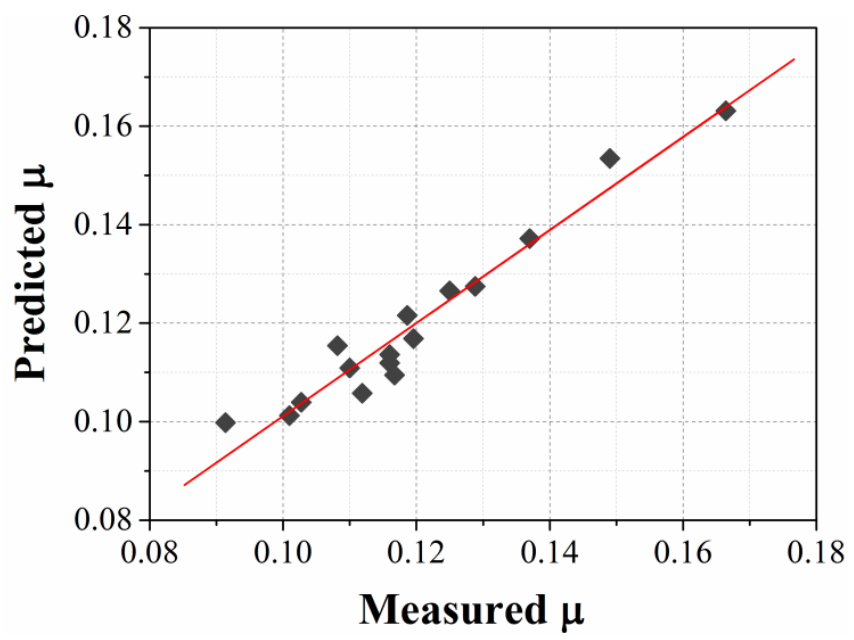

Fig. 9: Predicted average $\operatorname{COF}(\bar{\mu})$ versus measured $\bar{\mu}$ for textured cast iron.

Based on the above analyses, it is seen that $\bar{\mu}$ is mostly affected by the interactions between factors, and the only significant main factors are the diameter $(d)$ and the area fraction $(f)$. This provides all necessary information to figure out how a given change in the micro-texture geometry impacts the coefficient of friction under starved lubrication conditions. Also, the information obtained from this model is essential to get a fundamental understanding of the overall tribological behavior.

From the bar chart in Fig. 8b, it is seen that the diameter of micro-textures $(d)$ displays the most significant effect on $\bar{\mu}$ with a relative half-effect $(R H E)$ value of about $R H E_{d} \approx 9 \%$. Its positive effect on the COF combined with its interactions implies that increasing the diameter of the micro-textures would lead to a higher COF. This is actually in agreement with the numerical simulation of Nanbu et 
al. [18], which shows a stronger enhancement of the load lifting effect for narrow micro-textures as compared to wider structures.

Experimental results of Qiu and Khonsari [38] and the numerical work of Yu et al. [39] have shown that the length of micro-textures have a significant effect on $\bar{\mu}$. In this work, the length with $R H E_{l} \approx-1.5 \%$ is found to have a small impact on the COF. However, from Fig. 8 b, it can be seen that the interaction of the length and sliding direction $(l \alpha)$ has a great impact on $\bar{\mu}\left(R H E_{l \alpha}=5.4 \%\right)$. Fig. 10 illustrates the contour plots for interaction terms affecting the COF. As shown in Fig. 10a, $\bar{\mu}$ is small $(<0.111)$ for long micro-textures having length of $500 \mu \mathrm{m}$ (or $l=1$ as coded value) and sliding nearly parallel $\left(15^{\circ}\right)$. This can be due to the fact that when sliding in the direction of textures, the lubricant flow resistance is reduced, which could explain the lower COF [40]. Yuan et al. [41] also observed a lower COF for grooves with the depth of $19 \mu \mathrm{m}$ and parallel to the sliding direction. With FEM analysis, they show lubricant from inside the grooves flowing into the contact area. The same principle can be applied for the long micro-textures studied in this work.

With a $R H E_{h f}$ of about $6.8 \%$, the interaction between the depth and the area fraction $(h f)$ is the strongest interaction (see Fig. 8b). As presented in Fig. 10b, $\bar{\mu}$ is low $(<0.115)$ in case of having deep micro-textures $(50 \mu \mathrm{m})$ and low area fraction $(5 \%)$ or shallow micro-textures $(10 \mu \mathrm{m})$ with high area fraction (10\%) (grey contours in Fig. 10). In contrast, when both the depth and the area fraction are at their maximum value (see dark red contour Fig. 10b), $\bar{\mu}$ is the highest $(>0.13)$. The $h f$ interaction can be correlated to the total volume of the micro-textures and the lubricant being replenished to the surface during sliding. Micro-textures with larger volumes can feed more lubricant to the surrounding un-textured surface and can trap more debris. This can reduce the average COF. On the other hand, under starved lubrication conditions, deep dimples become partly empty and hence act as "microtraps" removing the lubricant from the un-textured surface in their vicinity [20]. Therefore, it is interesting to investigate the correlation between the micro-texture volume relative to the surrounding un-textured area $\left(V_{\text {micro-texture }} / A_{u}\right)$ versus $\bar{\mu}$ (see Fig. 11). The volume of each micro-texture is measured using the 3D contour map data of the micro-textures, and $A_{u}$ is calculated as follows:

$$
A_{u}=\frac{A_{t}-N \cdot A_{i}}{N}
$$


when $A_{t}$ is a known contact area (in our case $65 \mathrm{~mm}^{2}$ ), $A_{i}$ is the area of a micro-texture and $N$ is the number of micro-textures on $A_{t}$. In this graph, at low values of $V_{\text {micro-texture }} / A_{u}$ (region I), $\bar{\mu}$ is high $(\sim 0.12-0.14)$. This is because when $V_{\text {micro-texture }} / A_{u}$ is small, there is not enough lubricant inside each micro-texture to feed its un-textured area around or the volume of each micro-texture is insufficient to gather the debris. On the other hand, for the high values of $V_{\text {micro-texture }} / A_{u}$ (region III), $\bar{\mu}$ again goes up (> 0.15) except for Tx6. Looking at the micro-texture geometry of the two samples showing high $\bar{\mu}$ (Tx5 and Tx7) reveals that both samples have large diameters and deep micro-textures. Thus, it can be concluded that these large and deep micro-textures act as micro-traps for the lubricant. The exceptionally low $\bar{\mu}$ value of Tx6 ( 0.09), as compared to the other samples in region III, can be associated with an easier flow of the lubricant to the surrounding area. This is due to both the narrow and elongated micro-textures and sliding nearly parallel to the major axis of micro-textures. Finally, there is an optimum region (region II), where the lowest $\bar{\mu}$-values are located. In this region the microtextures contain enough lubricant to replenish the surrounding area or they are sufficiently large to gather the debris without acting as a "micro-trap" for the lubricant.

a

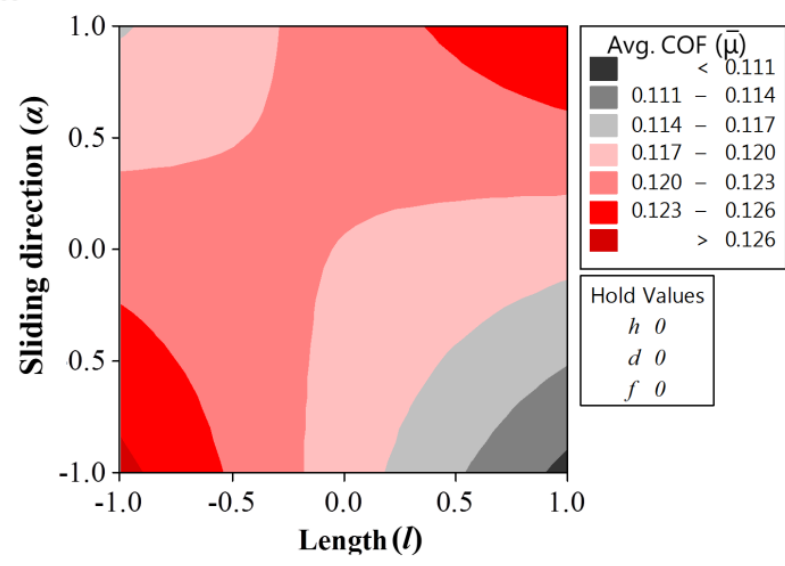

b

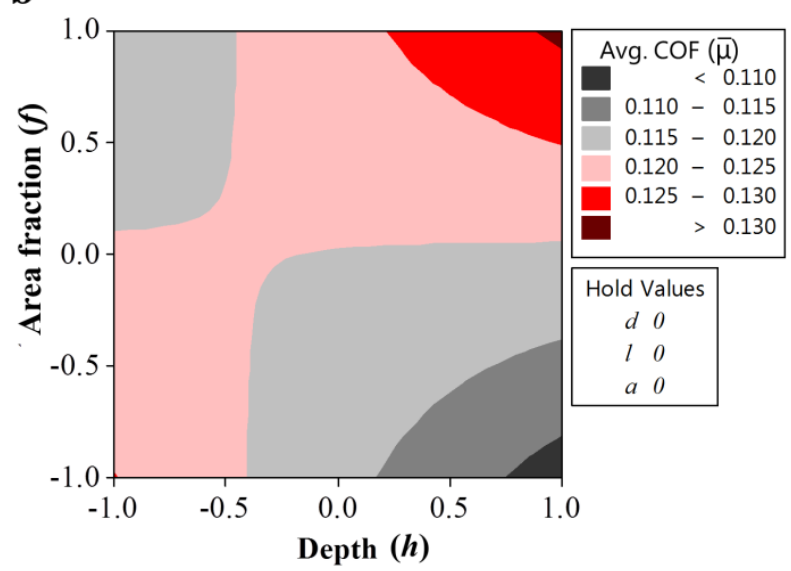

Fig. 10: Contour plot of average $\operatorname{COF}(\bar{\mu})$ versus interaction terms (a) $l \alpha$ and (b) $h f$. 


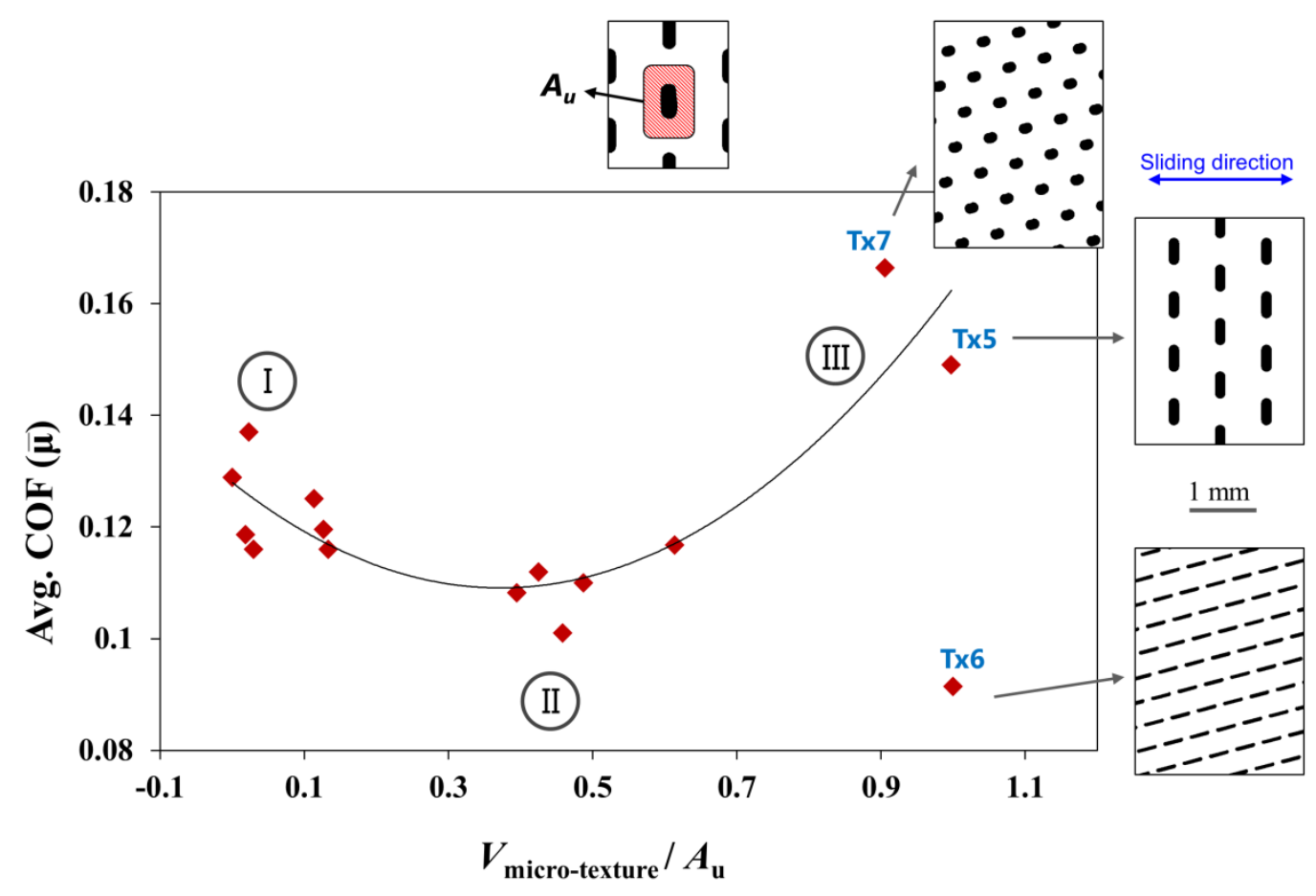

Fig. 11: Average coefficient of friction of textured cast iron versus the volume of each micro-texture $\left(V_{\text {micro-texture }}\right)$ over the un-textured area around $\left(A_{u}\right)$.

\subsection{Effect of texturing on the lifetime}

In this study, the lifetime $\left(T_{t}\right)$ is selected as the second response and defined as the sliding time until failure happens. Failure is considered to take place when a sharp increase in the COF is detected, as already shown in Fig. 5. Lifetime values $\left(T_{t}\right)$ are given in Table 2 . The same analysis procedure is performed to determine the effect of geometrical texture parameters on the lifetime of textured cast iron samples (results not presented). The ANOVA demonstrates that the lifetime model has an $R$ square value of 0.77 , considered to be acceptable within the field of tribology. However, it has a low predictability (Predicted- $R^{2}=0.41$ ) due to sudden onset of scuffing, resulting in a large scatter in the lifetime data. Although, this model has some limitations, very interesting information can be found by looking at the terms with significant effects and evaluating their influence on lifetime. The half-effect values $(H E)$ are presented in a bar chart in Fig. 12a in decreasing order. Similar to the DoE model on $\bar{\mu}$ presented in Section 3.1, the terms with the greatest effect on lifetime are the first-order interaction terms. The most significant terms are as follows: $l f(|H E|=116.5)>l \alpha(105.3)>h d(88.4)>h l(21.3)>$ $d l$ (18.6). Considering these significant terms, from Fig. 12a, it can be seen that longer lifetime is achieved by designing narrow $(d=-1)$ and elongated micro-textures $(l=+1)$ with a smaller area 
fraction $(f=-1)$. This can be explained by the higher load lifting effect of such structures as already discussed in Section 3.1. The interaction between the length and the sliding direction $(l \alpha)$ in Fig. 12b reveals that to have long lifetime, the sliding direction for these narrow and elongated micro-textures must be perpendicular to the structure (see in Fig. $12 \mathrm{~b}$, the dark green contour when $l=1$ ). The shortest lifetime is observed when the sliding direction is $\alpha=15^{\circ}$ for the elongated micro-textures (see the dark red contour in Fig. 12b). It is interesting to note that this combination displayed the lowest $\bar{\mu}$ in the analyses presented in Section 3.1. This can be explained by considering the lower resistance of the lubricant. On the one hand, it can reduce $\bar{\mu}$ due to an easier flow. On the other hand, it allows the lubricant to be pushed away from the contact more easily leading to earlier solid-solid contact and so increases the probability of an early failure. By optimizing the factors to both responses (low COF and long lifetime), the optimal micro-texture is found to be very close to the micro-texture of Tx2 with $h=50 \mu \mathrm{m}, d=100 \mu \mathrm{m}, l=500 \mu \mathrm{m}, f=5 \%$ and $\alpha=90^{\circ}$.

Fig. 13 shows the average lifetime for all textured samples studied in this work $(325 \pm 207 \mathrm{~min}$ for the total 25 samples) as compared to the average lifetime of 16 un-textured cast iron samples (177 $\pm 163 \mathrm{~min})$. Despite having a huge scatter for both textured and un-textured samples, calculations show that with a $95 \%$ confidence interval, there is a $148 \pm 113$ minutes difference between the average lifetime of textured and un-textured samples. It is important to note that the wide scatter in the lifetime of textured samples, apart from the typical scattering, can be also due to their different geometries. All in all, it is obvious that the micro-textures increase the lifetime of cast iron sliding under starved lubrication conditions. Nevertheless, it is hard to quantify the lifetime enhancement attributed to the surface texturing due to the large scatter in the lifetime results. To be able to do so, a large number of replicates are required to have confidence in the statistical results. Finally, based on the explanations given for Fig. 11 and the SEM image shown in Fig. 13, it can be concluded that both mechanisms: micro-reservoir for lubricant and traps for debris are acting simultaneously for the studied tribosystem. EDX measurements of wear debris are provided in the Appendix (Fig. A.4). However, full characterization of wear mechanisms of textured samples will be presented in another work by the same authors. 
a

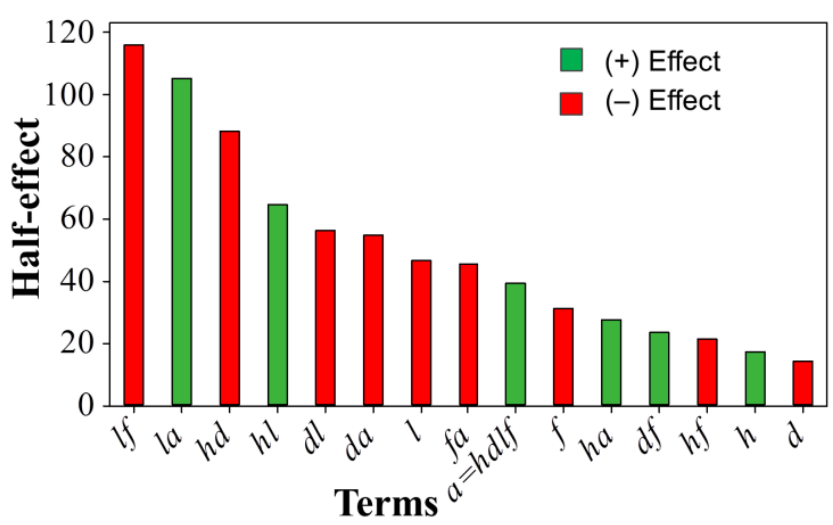

b

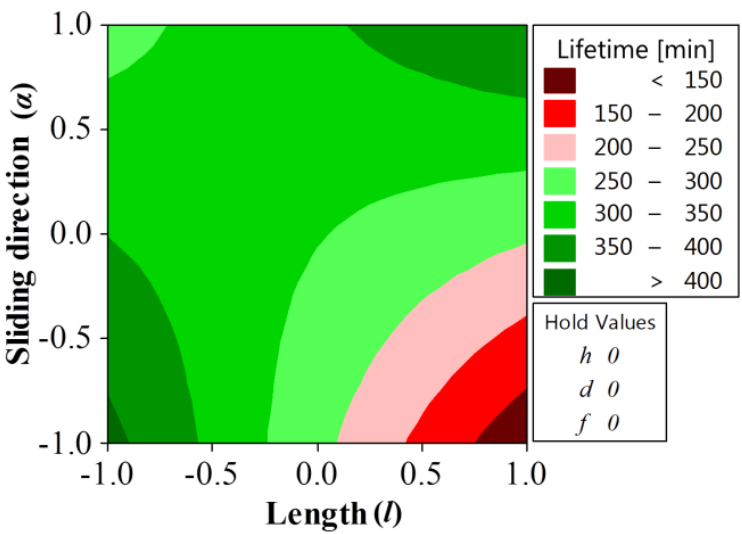

Fig. 12: (a) Half-normal probability plot for lifetime response $\left(T_{t}\right)$ and (b) Contour plot of $T_{t}$ versus interaction term $(l \alpha)$. ( + effects appear with $+\operatorname{sign}\left(+a_{i}\right.$ or $\left.+a_{i j}\right)$ in Eq.(1) and thus increase the response $(Y)$ and $(-)$ effects appear as $-a_{i} /-a_{i j}$ in this equation.

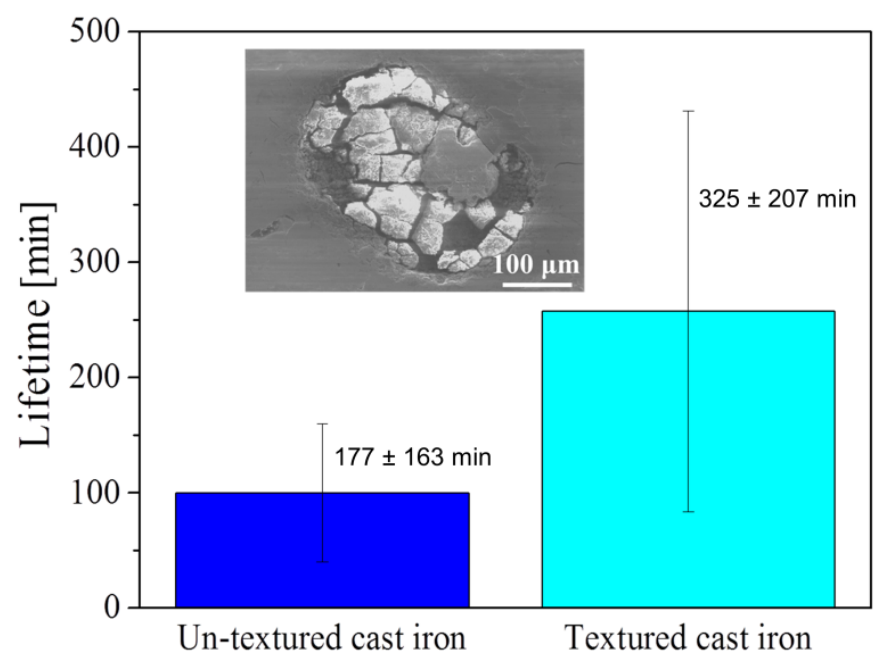

Fig. 13: Lifetime comparison of un-textured and textured cast iron sliding under the starved lubrication condition (inside: SEM image of one micro-texture filled by wear debris).

\section{Conclusions}

In this study, the tribological performance of textured cast iron samples was analyzed using a design of experiments (DoE) approach. The DoE was developed based on a fractional factorial design to study the effect of geometrical parameters (diameter, depth, length, area fraction and sliding direction) of the micro-textures on the average coefficient of friction and the sample lifetime. Flat-onflat tribo-tests were carried out for surface textured grey cast iron reciprocating against a hardened $42 \mathrm{CrMo6}$ steel counter-body under starved lubrication conditions. It is found that the geometrical parameters of micro-textures interact predominantly and in a complex manner. Thus, using 
conventional analyses or ignoring the factor interactions can lead to false conclusions. The results showed that the diameter $(d)$ and the area fraction $(f)$ of micro-textures are the only main factors influencing the average coefficient of friction $(\bar{\mu})$ significantly. Although the length $(l)$, the sliding direction $(\alpha)$ and the depth $(h)$ do not show any significant impact on the responses, their interactions were considerably affecting $\bar{\mu}$ and the lifetime. The lowest coefficient of friction was observed for the narrow $(d=100 \mu \mathrm{m})$ and long micro-textures $(l=500 \mu \mathrm{m})$ sliding with $15^{\circ}$ while this structure exhibits a relatively short lifetime. The ratio of the volume of a micro-texture over its un-textured area around $\left(V_{\text {micro-texture }} / A_{u}\right)$ is also found to have a dominant effect on $\bar{\mu}$. This parameter is suggested as a new geometrical parameter to be considered for designing new micro-textures. The DoE analysis of $\bar{\mu}$ and the lifetime suggests that micro-textures close to Tx2 design provides an optimal solution to have a low coefficient of friction and long lifetime. Its geometrical parameters are: a depth of $50 \mu \mathrm{m}, \mathrm{a}$ diameter of $100 \mu \mathrm{m}$, a length of $500 \mu \mathrm{m}$, an area fraction of $5 \%$ and a sliding direction of $90^{\circ}$ relative to the major axis of micro-textures.

\section{Acknowledgments}

The authors would like to thank the Swiss Commission for Technology and Innovation (CTI, project $\mathrm{N}^{\circ}$ 12358.1 PFIW-IW) and the industrial partners for the financial support of this work. Special thanks to Dr. Sergio Graca for his assistance in the early stage of this work. Dr. Jean-Marie Fuerbringer of EPFL is acknowledged for the discussion on DoE model. Motorex AG is acknowledged for providing pure poly-alpha-olephin used in this study.

\section{References}

[1] M. Priest, C.M. Taylor, Automobile engine tribology - approaching the surface, Wear, 241 (2000) 193-203.

[2] F. Klocke, O. Auer, A. Zaboklicki, Laser structuring reduces friction and wear, Prod. Engineer., 2 (1998) 31-34.

[3] I. Etsion, State of the art in laser surface texturing, J. Tribol.-T ASME, 127 (2005) 248-253.

[4] S.P. Mishra, A.A. Polycarpou, Tribological studies of unpolished laser surface textures under starved lubrication conditions for use in air-conditioning and refrigeration compressors, Tribol. Int., 44 (2011) 1890-1901.

[5] X.L. Wang, K. Kato, K. Adachi, K. Aizawa, Loads carrying capacity map for the surface texture design of SiC thrust bearing sliding in water, Tribol. Int., 36 (2003) 189-197.

[6] D.B. Hamilton, J.A. Walowit, C.M. Allen, A Theory of Lubrication by Micro-Irregularities, J. Basic Eng.-T ASME, 88 (1966) 177-185. 
[7] K. Steinhoff, W. Rasp, O. Pawelski, Development of deterministic-stochastic surface structures to improve the tribological conditions of sheet forming processes, J. Mater. Process. Technol., 60 (1996) 355-361.

[8] S.W. Lo, T.C. Horng, Lubricant permeation from micro oil pits under intimate contact condition, J. Tribol.-T ASME, 121 (1999) 633-638.

[9] M. Fowell, A.V. Olver, A.D. Gosman, H.A. Spikes, I. Pegg, Entrainment and inlet suction: Two mechanisms of hydrodynamic lubrication in textured bearings, J. Tribol.-T ASME, 129 (2007) 336347.

[10] N.P. Suh, M. Mosleh, P.S. Howard, Control of Friction, Wear, 175 (1994) 151-158.

[11] H. Tian, N. Saka, N.P. Suh, Boundary Lubrication Studies on Undulated Titanium Surfaces, Tribol. T., 32 (1989) 289-296.

[12] N. Saka, H. Tian, N.P. Suh, Boundary Lubrication of Undulated Metal Surfaces at Elevated Temperatures, Tribol. T., 32 (1989) 389-395.

[13] X.L. Wang, K. Kato, K. Adachi, K. Aizawa, The effect of laser texturing of SiC surface on the critical load for transition of water lubrication mode from hydrodynamic to mixed, Tribol. Int., 34 (2001) 703-711.

[14] X.L. Wang, K. Kato, K. Adachi, The lubrication effect of micro-pits on parallel sliding faces of SiC in water, Tribol. T., 45 (2002) 294-301.

[15] H.L. Costa, I.M. Hutchings, Hydrodynamic lubrication of textured steel surfaces under reciprocating sliding conditions, Tribol. Int., 40 (2007) 1227-1238.

[16] D. Braun, C. Greiner, J. Schneider, P. Gumbsch, Efficiency of laser surface texturing in the reduction of friction under mixed lubrication, Tribol. Int., 77 (2014) 142-147.

[17] U. Pettersson, S. Jacobson, Influence of surface texture on boundary lubricated sliding contacts, Tribol. Int., 36 (2003) 857-864.

[18] T. Nanbu, N. Ren, Y. Yasuda, D. Zhu, Q.J. Wang, Micro-textures in concentrated conformalcontact lubrication: Effects of texture bottom shape and surface relative motion, Tribol. Lett., 29 (2008) 241-252.

[19] I. Etsion, L. Burstein, A model for mechanical seals with regular microsurface structure, Tribol. T., 39 (1996) 677-683.

[20] G. Ryk, Y. Kligerman, I. Etsion, Experimental investigation of laser surface texturing for reciprocating automotive components, Tribol. T., 45 (2002) 444-449.

[21] A.H. Garrido, R. González, M. Cadenas, A.H. Battez, Tribological behavior of laser-textured NiCrBSi coatings, Wear, 271 (2011) 925-933.

[22] A. Kovalchenko, O. Ajayi, A. Erdemir, G. Fenske, I. Etsion, The effect of laser surface texturing on transitions in lubrication regimes during unidirectional sliding contact, Tribol. Int., 38 (2005) 219225.

[23] K. Hinkelmann, O. Kempthorne, Factorial Experiments: Basic Ideas, Design and Analysis of Experiments, John Wiley \& Sons, Inc., 2007, pp. 419-495.

[24] D.C. Montgomery, Design and Analysis of Experiments, seventh ed., John Wiley \& Sons, Ltd., 2009.

[25] N. Ren, T. Nanbu, Y. Yasuda, D. Zhu, Q. Wang, Micro textures in concentrated-conformalcontact lubrication: Effect of distribution patterns, Tribol. Lett., 28 (2007) 275-285.

[26] B. Kim, Y.H. Chae, H.S. Choi, Effects of surface texturing on the frictional behavior of cast iron surfaces, Tribol. Int., 70 (2014) 128-135.

[27] D. Yan, N. Qu, H. Li, X. Wang, Significance of Dimple Parameters on the Friction of Sliding Surfaces Investigated by Orthogonal Experiments, Tribol. T., 53 (2010) 703-712.

[28] H. Yu, W. Huang, X. Wang, Dimple patterns design for different circumstances, Lubr. Sci., Published online in Wiley Online Library, DOI: 10.1002/1s.168 (2011).

[29] G.E.P. Box, W.G. Hunter, J. Stuart, An introduction to design, data analysis and model building, Wiley Series in Probability and Mathematical Statistics New York, 1978.

[30] W.F. Bowman, G.W. Stachowiak, A review of scuffing models, Tribol. Lett., 2 (1996) 113-131.

[31] P.J. Blau, On the nature of running-in, Tribol. Int., 38 (2005) 1007-1012.

[32] K.C. Ludema, A review of scuffing and running-in of lubricated surfaces, with asperities and oxides in perspective, Wear, 100 (1984) 315-331. 
[33] I.M. Hutchings, Tribology, Friction and Wear of Engineering Materials, Edward Arnold, London, 1992.

[34] F. Saeidi, S.A. Shevchik, K. Wasmer, Automatic detection of scuffing using acoustic emission, Tribol. Int., 94 (2016) 112-117.

[35] P. Olander, S. Jacobson, Scuffing resistance testing of piston ring materials for marine two-stroke diesel engines and mapping of the operating mechanisms, Wear, 330-331 (2015) 42-48.

[36] E.J. Abbott, F.A. Firestone, On specifying surface quality, Mech. Eng., 55 (1933) 569.

[37] G.E.P. Box, W.G. Hunter, J.S. Hunter, Statistics for experimenters John Wiley \& Sons, Inc., 2005.

[38] Y. Qiu, M.M. Khonsari, Experimental investigation of tribological performance of laser textured stainless steel rings, Tribol. Int., 44 (2011) 635-644.

[39] H. Yu, H. Deng, W. Huang, X. Wang, The effect of dimple shapes on friction of parallel surfaces, Proceedings of the Institution of Mechanical Engineers, Part J: Journal of Engineering Tribology 225 (2011) 693-703.

[40] F. Meng, R. Zhou, T. Davis, J. Cao, Q. Wang, D. Hua, J. Liu, Study on effect of dimples on friction of parallel surfaces under different sliding conditions, Appl. Surf. Sci., 256 (2010) 2863-2875.

[41] S. Yuan, W. Huang, X. Wang, Orientation effects of micro-grooves on sliding surfaces, Tribol. Int., 44 (2011) 1047-1054. 